\title{
ENSINO DE PRODUÇÃO ESCRITA DO GÊNERO RESENHA CRÍTICA: A ATUAÇÃO DO PROFESSOR E DO LIVRO DIDÁTICO DE PORTUGUÊS
}

\author{
Sílvio Ribeiro da Silva (UFG) \\ shivonda@gmail.com
}

\section{Introdução}

Neste texto, apresento uma reflexão acerca de como uma professora desenvolve a proposta de produção escrita do gênero resenha críti$c a$, apresentada pelo livro didático de Português (LDP) "Português Linguagens", do $8^{\circ}$ ano, e também como os alunos apresentam o que aprenderam do gênero em suas produções escritas. Com isso, mostro se a condução da professora, aliada às orientações do LDP, colabora para a aprendizagem do gênero pelos alunos, visando à formação de produtores de textos argumentativos.

Para chegar àquilo que proponho, apresento um estudo baseado nos procedimentos metodológicos da linguística aplicada (LA) com base interpretativista, focalizando o processo de uso da linguagem no ensinoaprendizagem de produção de textos escritos em língua materna. O corpus de análise é constituído pela proposta do LDP para a produção escrita da resenha crítica, pela aula em que a professora desenvolveu as atividades relacionadas à proposta e pelos respectivos textos produzidos pelos alunos.

A análise dos dados aponta que os alunos conseguem, de maneira geral, elaborar a resenha crítica, levando para o seu texto possíveis reflexos do conhecimento extraescolar sobre ele, tendo em vista marcas estilísticas e temáticas detectadas nos mesmos, não ensinadas pelo LDP, nem pela professora, o que dá indícios da necessidade de melhoria na elaboração do material didático e na formação do professor. 


\section{Abordagem do LDP para o gênero resenha crítica}

Para a realização de um estudo acerca da produção escrita no LDP, inicialmente é necessário que se tenha um parâmetro de observação a respeito do que seria um livro didático eficaz no ensino de produção de textos, independente do agrupamento ao qual os gêneros estudados se enquadrem.

Uso como parâmetro as ideias de Marcuschi \& Cavalcanti (2005), defensoras de que o bom livro didático de língua portuguesa é aquele que permite a problematização das práticas de letramento, oferecendo ao usuário, no caso o aluno, a oportunidade de participar de momentos diversificados de trabalho textual em contextos de uso. Além disso, o bom livro opera com gêneros do discurso ${ }^{8}$ que circulam socialmente, considerandose aí as práticas discursivas dos interlocutores. Esse enfoque, segundo as autoras, está diretamente interligado à noção de letramento visto como "o estado ou a condição que adquire um grupo social ou um indivíduo como consequência de ter-se apropriado da escrita" (SOARES, 1998, apud MARCUSCHI \& CAVALCANTI, 2005). A noção de língua enquanto atividade histórica e situada, na qual se acham envolvidos os usuários para construir e reconstruir permanentemente uma versão pública do mundo, também é imprescindível, segundo as autoras, para o enfoque necessário a um trabalho eficaz feito por um LDP.

A resenha crítica é apresentada aos alunos no LDP do $8^{\circ}$ ano na Unidade $\mathrm{I}^{9}$. Quando dá início às orientações para sua apropriação, o LDP, primeiramente, apresenta um texto crítico seguido de uma série de questões a seu respeito. Essas questões abordam tanto informações veiculadas pelo texto, quanto aspectos do estilo do gênero ou da sua estrutura composicional. Para ilustrar como é o trabalho com o gênero no LDP, apresento duas dessas questões.

(p. 58)

$$
\text { (...) }
$$

\footnotetext{
${ }^{8}$ As autoras usam a noção de gênero textual. Porém, por concordar com as ideias desenvolvidas pelos estudos voltados para a noção discursiva, usei o termo discursivo, uma vez que considero gênero discursivo todas as formas de enunciado que variam de acordo com as esferas sociais de comunicação, levando em conta a interação entre interlocutores e a enunciação.

${ }^{9}$ Cada um dos volumes da coleção possui quatro unidades e cada unidade é formada por três capítulos e um capítulo especial: o Intervalo.
} 
6. Observe a linguagem empregada no texto.

\section{(..)}

b) Que tipo de variedade linguística foi empregada?

c) Considerando que a crítica foi publicada num jornal de grande circulação, levante hipóteses: Que razões haveria para ser empregada essa variedade linguística, uma vez que os livros são infanto-juvenis?

$$
\text { (...) }
$$

7. O texto expressa a opinião do crítico que avalia a obra. Assim, a crítica pode ser mais pessoal, o que ocorre quando o autor se coloca no texto de forma explícita, expressando expressões como $\mathrm{Na}$ minha opinião, Eu acho que, Eu penso que etc., ou pode ser impessoal, o que acontece quando o autor se coloca de forma indireta, empregando a $3^{\text {a }}$ pessoa. A crítica em estudo é pessoal ou impessoal?

A questão 6 é o tipo de questão que aborda aspectos ligados ao estilo do gênero. Faltou orientar o professor a chamar a atenção do aluno para o fato de que certos gêneros possuem um estilo característico, o qual não deve ser "ferido", uma vez que, segundo Bakhtin (1979, p. 284-5),

Cada esfera conhece seus gêneros, apropriados à sua especificidade, aos quais correspondem determinados estilos. Uma dada função (científica, técnica, ideológica, oficial, cotidiana) e dadas condições, específicas para cada uma das esferas da comunicação verbal, geram um dado gênero, ou seja, um dado tipo de enunciado, relativamente estável do ponto de vista temático, composicional e estilístico. $\mathrm{O}$ estilo é indissociavelmente vinculado a unidades temáticas determinadas e, o que é particularmente importante, a unidades composicionais: tipo de estruturação e de conclusão de um todo, tipo de relação entre o locutor e os outros parceiros da comunicação verbal (relação com o ouvinte, ou com o leitor, com o interlocutor, com o discurso do outro etc.).

A questão 7 deixa a desejar quando perde a oportunidade de esclarecer para o aluno recursos discursivos ligados à interlocução. Sem qualquer esclarecimento anterior, fica difícil para o aluno conseguir entender o emprego da $3^{\text {a }}$ pessoa, bem como os efeitos de sentido que estão por trás do apagamento feito pelo sujeito enunciador em seu discurso. Caberia ao professor, mesmo não havendo orientação para isso, oferecer esses esclarecimentos, elucidando ao aluno os efeitos de sentido pretendidos por um autor/locutor quando ocorre esse apagamento relacionado às referências da situação material de produção: marcas de pessoa, tempo e lugar.

Para que o aluno de fato produza uma resenha crítica, o LDP traz um plano de elaboração, que deverá ser seguido para o desenvolvimento da atividade. São apresentadas duas propostas para que seja escolhida uma. Porém, sugere-se ao professor que, havendo tempo, trabalhe as duas. 


\section{FACULDADE DE FormaÇÃo de PROFESSORES}

(p. 59)

1. Façam a crítica de um objeto cultural da preferência de todos: uma peça de teatro em cartaz na cidade, um livro, um filme, um CD-ROM, um show musical, uma exposição de arte. Antes de produzirem o texto, assistam à peça ou ao show, leiam o livro, ouçam o $\mathrm{CD}$, joguem o jogo no computador, visitem a exposição.

2. Façam a crítica de um dos textos teatrais produzidos pelos colegas (esses textos foram produzidos na unidade anterior).

Dentre as instruções oferecidas, uma faz referência específica ao leitor do texto.

(p. 59)

\section{(..)}

c) Antes de começarem a redigir, pensem no público leitor e em qual será o veículo do texto: o mural ou jornal da escola ou da classe ou um painel na feira Fazendo humor e teatro (p. 76), proposta no capítulo Intervalo desta unidade.

\section{(...)}

$\mathrm{Na}$ indicação do público leitor/destinatário, o LDP esclarece ao aluno que se trata de todos os alunos, professores e funcionários da escola, uma vez que o texto irá para o mural, local onde, certamente, todas as pessoas que circulam pelo ambiente escolar podem ler o que está exposto.

Quando a atividade solicita que o aluno pense no leitor e ainda indica o local por onde o texto circulará, visualiza-se uma provável aproximação do LD à particularidade do enunciado referente à sua relação com o próprio locutor (autor) e com os outros parceiros da comunicação verbal (BAKHTIN, 1979). Esta particularidade está associada à expressividade, a qual constitui um recurso de expressão emotivo-valorativa do locutor, quanto ao tema de seu discurso. No enunciado, a expressividade ganha significado, é determinada pelo contexto e não possui valor normativo.

Como no enunciado proposto para elaboração há um destinatário (ou vários), o LD orienta, indiretamente, o aluno para que, ao elaborar este enunciado, o qual presume sempre uma resposta que influencia sua fala, leve em consideração o destinatário, as informações que ele tem, suas opiniões, seus conhecimentos e convicções. Segundo Bakhtin (1979), cada gênero do discurso, em cada esfera de comunicação verbal, tem uma concepção de destinatário que, de certa forma, determina o gênero e suas nuances composicionais, estilísticas e temáticas. 
Faltou aproveitar a oportunidade para apresentar ao aluno a questão de que o lugar social ocupado pelos interlocutores, a representação que um tem do outro, as representações sobre o tema no contexto escolar, bem como a esfera e o suporte por onde o texto circulará farão com que o seu estilo, o uso da variedade linguística, o tom (formal ou não) sejam de uma forma e não de outra.

\section{Aula sobre a resenha crítica}

A aula aconteceu no dia 23 de abril de 2010, numa escola pública estadual da cidade de Jataí Goiás. Foram usadas duas aulas geminadas, perfazendo um total de 100 minutos.

Inicialmente a professora efetuou a leitura do livro "Ritinha Troca-Bolas", de Pedro Bandeira e Osnei F. Rocha, publicado pela Editora Moderna, em 1997, mostrando suas ilustrações. A docente solicitou que alguns alunos recontassem a história oralmente. Em seguida, pediu que dessem sua opinião sobre o livro. Os alunos demonstraram ter gostado da história, achando-a bastante humorística. Disseram que era indicada para crianças de até 12 anos, aproximadamente; a mesma faixa etária deles.

Posteriormente, a professora fez uma recapitulação com os alunos sobre as características do gênero resenha. Escreveu um breve esquema no quadro, dizendo a eles que o principal objetivo de uma resenha é evidenciar as qualidades ou defeitos de uma obra. Enfatizou a necessidade de se analisar criticamente o objeto estudado. Ainda disse o que ela considera como sendo a utilidade de uma resenha: oferecer subsídios ao leitor para que ele decida se deve ou não ler a obra analisada.

Numa aula anterior, a professora havia trabalhado com a classe a resenha crítica "Quadrinhos Resgatam Shakespeare", presente no LDP (p. 57). Porém, as questões que o LDP traz sobre a resenha não foram desenvolvidas, segundo ela mesma, por acreditar que não haveria tempo suficiente para respondê-las e depois elaborar o texto. Além disso, segundo afirmação sua dada numa conversa informal, pelo fato de os alunos não terem demonstrado interesse pela resenha crítica, à qual as questões dizem respeito, a atividade poderia se tornar enfadonha. Porém, ela afirmou ter se arrependido depois pelo não desenvolvimento da atividade, porque algumas das questões são, segundo ela, inteligentes.

Na sequência, a professora pediu que os alunos abrissem o LDP na página 56 para se lembrarem das características de uma resenha críti- 


\section{FACULDADE DE FormaÇÃo de PROFESSORES}

$c a$. Então, escreveu no quadro os dados descritivos da obra a ser resenhada (Ritinha Troca-Bolas): título, autoria, editora e ano de publicação. Logo, solicitou aos alunos que redigissem uma resenha crítica sobre o livro. Todos, sem exceção, produziram a resenha.

\section{Considerações sobre o texto produzido pelos alunos}

O LDP traz duas opções para a produção da resenha crítica: (1) fazer a crítica de um objeto cultural: peça de teatro, livro, filme; ou (2) a crítica de um dos textos teatrais solicitados no capítulo anterior.

A opção pela produção da resenha crítica do livro, ao invés dos textos teatrais produzidos pelos próprios alunos, foi da professora. Foram produzidos pela classe 31 textos. $97 \%$ deles começam seguindo o roteiro apresentado pela professora na lousa, o qual determinava o início da resenha crítica a partir do título, seguido de autoria, editora, ano, edição e volume.

Ainda em relação ao roteiro apresentado pela professora, grande parte dos alunos apresenta um resumo do livro resenhado (59\%). A maioria desses resumos aponta informações que os alunos, certamente, acharam mais pertinentes para persuadir o suposto leitor. Por se tratar de uma resenha, apresentar um resumo da obra constitui num importante recurso persuasivo, uma vez que o leitor, lendo o resumo, teria mais condições de avaliar se a leitura do livro resenhado valeria ou não a pena.

No entanto, $13 \%$ dos alunos não resumiram a história propriamente, limitando-se a relatar uma parte específica do livro, a história de um gato que caiu em um tanque com água. $28 \%{ }^{10}$ dos alunos mencionaram que o livro resenhado faz intertexto com outras histórias infantis. A menção ao intertexto também se constitui em uma estratégia persuasiva interessante, tendo em vista que pode gerar no leitor da resenha a expectativa de que o livro apresentado, ao dialogar com outros textos infantis, pode ser rico.

Por mostrar justificativas frágeis para as colocações, esta produção demonstrou que os alunos dispunham de recursos argumentativos limitados para trazer para junto de si o auditório, ganhando a sua adesão à

\footnotetext{
${ }^{10}$ A soma dos dados percentuais apresentados não totaliza $100 \%$ por conta de haver repetição de itens em mais de um texto.
} 
ideia apresentada. Uma hipótese para isso poderia ser a certa distância que os alunos têm com a resenha crítica, por ser este gênero do discurso pouco comum em suas práticas de letramento.

Mesmo o LD tendo deixado passar algumas boas oportunidades de instrumentalizar o aluno para a construção de um texto argumentativo eficiente, fez bem ao indicar na proposta de produção a finalidade comunicativa do texto, seu interlocutor e a forma de seu desenvolvimento.

Tanto nas orientações trazidas pelo $\mathrm{LD}$, quanto nas oferecidas pela professora, pode-se perceber ausência de orientação exata para a construção de argumentos eficientes. Tanto um quanto o outro se atém muito mais a orientações sobre o estilo e a estrutura composicional do gênero apresentado para a produção.

Essas perdas do LD acabam por desfavorecer a apropriação do gênero resenha crítica por parte dos alunos, tendo em vista que, segundo Dolz \& Schneuwly (2004, p. 53), "as intervenções formalizadas nas instituições escolares são fundamentais para a organização das aprendizagens em geral e para o processo de apropriação de gêneros em particular".

\section{Considerações finais}

Como ponto positivo da proposta do LDP para a produção da resenha crítica, ressalto a explicitação do contexto social de circulação, mesmo que ele seja a própria escola. Por mais que inexista valorização do contexto externo, a sua indicação pode fazer com que o aluno compreenda que os textos são feitos para serem lidos e para "habitar" certos contextos, certas esferas de atividade humana.

No entanto, reduzir o texto a circular apenas em ambiente escolar traz certos problemas, dentre eles o fato de essa produção se enquadrar na categoria redação. Para Marcuschi \& Cavalcante (2005), a característica básica da redação é a sua restrição ao ambiente escolar. As autoras chamam esse tipo de redação de endógena, uma vez que se origina e se esgota nela mesma. As autoras afirmam que o professor solicita a produção de um texto, que é feito pelo aluno com vias a cumprir uma tarefa meramente escolar. O professor lê o texto, visando atribuir a ele uma nota, e o devolve ao aluno, que considera o processo encerrado e não retoma a produção feita outrora. Esse texto é abordado numa perspectiva meramente pedagógica, passando a ser caracterizado como redação (MAR- 


\section{FACULDADE DE FormaÇÃo de PROFESSORES}

CUSCHI, 2004, apud MARCUSCHI \& CAVALCANTE, 2005), ganhando, assim, o status de um novo gênero do discurso.

Outro ponto positivo é a indicação do leitor destinatário do texto. Sobre isso, convém lembrar as ideias de Perelman \& Olbrechts-Tyteca (2005), para quem o discurso argumentativo consistiria em um espaço em que se busca um efeito imediato sobre a audiência (o auditório), de modo a levá-la a concordar com os pontos de vista apresentados. Assim, é imprescindível que o orador tenha uma imagem adequada do auditório.

Um ponto a ser observado diz respeito à apresentação do plano de elaboração do texto a ser produzido pelo aluno. Este plano tende a formatar os textos, como se a construção de um discurso argumentativo, oral ou escrito, seguisse sempre o mesmo roteiro. Os argumentos vão sendo colocados em decorrência dos objetivos traçados, das características do destinatário, da tese que se pretende defender e dependem, mais ainda, da situação argumentativa. Se por um lado esse plano pode funcionar com um guia didático para produtores de texto em formação, por outro pode ser tomado pelo professor e pelo aluno como um esquema fechado, levando à homogeneização dos textos (MARCUSCHI \& CAVALCANTE, 2005), o que pode ser prejudicial ao aluno.

Em se tratando da aula, em sua condução, a professora assumiu a função de organizadora do contexto pedagógico, dando as coordenadas sobre a atividade a ser realizada pelos alunos. Um ponto a ser destacado em relação a ela diz respeito às suas tentativas em estimular nos alunos a construção do conhecimento.

Sobre os textos produzidos pelos alunos, o ponto mais marcante diz respeito à dificuldade de alguns na construção da argumentação. Isso não significa que os alunos não sabem argumentar. Certamente eles elaboram textos argumentativos orais (gêneros primários do discurso) eficientemente, mas ainda encontram dificuldade na sua produção escrita. Essa dificuldade para a escrita pode ser decorrente de certa ineficiência do LDP e da abordagem da professora no momento de oferecer aos alunos condições de produção eficientes para a elaboração de um bom texto escrito.

Como a professora não aborda a argumentação em si, nem o LDP dá maiores explicações sobre isso no Manual do Professor, temos uma indicação de que os alunos que argumentam o fazem adotando e adaptando o seu conhecimento extra-escolar sobre a argumentação. A profes- 
sora se prendeu mais à exploração dos aspectos estruturais e composicionais do texto argumentativo.

Mesmo muitos dos alunos sendo capazes de argumentar, convêm enfatizar que é na escola que eles mais podem refletir sobre estratégias diversificadas para apresentação e defesa de ponto de vista (LEAL \& MORAES, 2006). É na escola, também, que eles devem aprender e desenvolver outras estratégias argumentativas, ampliando seu(s) letramento(s); estratégias essas que sejam adequadas às variadas finalidades que nos exigem a elaboração de textos em diversas esferas de atividade humana.

A exposição aos mais variados gêneros deve ser feita desde sempre. É isso que dizem Dolz, Noverraz \& Schneuwly (2004), para quem a atividade de produzir textos é um processo complexo, sendo sua aprendizagem, por conta disso, lenta e longa. Os autores propõem que seja iniciado precocemente o trabalho com variados gêneros para assegurar o domínio dos principais no final do Ensino Fundamental. Não se trata, segundo os autores, de levar os alunos iniciantes a fazer o que estava anteriormente previsto para os mais experientes. A retomada dos mesmos gêneros, em etapas posteriores, pode se constituir num importante instrumento de observação do efeito do ensino em longo prazo, assegurando uma construção contínua por parte dos alunos, uma vez que os comportamentos complexos exigem tempo.

Análises como esta e tantas outras desenvolvidas nos cursos de pós-graduação, especialmente em linguística aplicada, demonstram de que forma os objetos de ensino abordados pelo LDP estão sendo trabalhados e internalizados pelos alunos. Demonstram, também, que a prática do trabalho do professor e a forma como utiliza o LDP na classe precisam passar por mudanças que devem ser implantadas na política de formação docente e de elaboração de materiais didáticos.

\section{REFERÊNCIAS BIBLIOGRÁFICAS}

BAKHTIN, M. Os gêneros do discurso. In __. Estética da criação verbal. São Paulo: Martins Fontes, 1979, p. 277-326.

CEREJA, W. R. \& MAGALHÃES, T. C. Português - linguagens: $5^{\mathrm{a}}$ à $8^{\mathrm{a}}$ séries. São Paulo: Atual, 2006.

DOLZ, J., NOVERRAZ, M.; SCHNEUWLY, B. Sequências didáticas 
para o oral e a escrita: apresentação de um procedimento. In: SCHNEUWLY, B., DOLZ, J. et al. Gêneros orais e escritos na escola. Campinas: Mercado de Letras, 2004, p. 95-128.

DOLZ, J. \& SCHNEUWLY, B. Gêneros e progressão em expressão oral e escrita: elementos para reflexões sobre uma experiência suíça (francófona). In: SCHNEUWLY, B., DOLZ, J. et al. (Orgs.) Gêneros orais e escritos na escola. Campinas: Mercado de Letras, 2004, p. 41-70.

LEAL, T. F.; MORAIS, A. G. A argumentação em textos escritos: a criança e a escola. Belo Horizonte: Autêntica, 2006.

MARCUSCHI, E.; CAVALCANTE, M. Atividades de escrita em livros didáticos de língua portuguesa: perspectivas convergentes e divergentes. In: COSTA VAL, M. da G.; MARCUSCHI, B. (Orgs.). O livro didático de língua portuguesa - letramento, inclusão e cidadania. Belo Horizonte: Autêntica, 2005, p. 237-260.

PERELMAN, C.; OLBRECHTS-TYTECA, L. Tratado da argumentação: a nova retórica. São Paulo: Martins Fontes, 2005. 